\title{
Reggio Emilia Inspired Philosophical Teacher Education in the Anthropocene: Posthuman Child and the Family (Tree)
}

\author{
Karin Murris, Rose-Anne Reynolds, and Joanne Peers
}

\begin{abstract}
Karin Murris is full professor of pedagogy and philosophy at the School of Education at the University of Cape Town, South Africa. Grounded in philosophy as an academic discipline, as a teacher educator her main research interests are in posthuman intraactive pedagogies such as philosophy with children and Reggio Emilia, school ethics, and postqualitative research methods. She is principal investigator of the Decolonising Early Childhood Discourses: Critical Posthumanism in Higher Education research project funded by the South African National Research Foundation (NRF). Her articles can be downloaded from https://uct.academia.edu/ KarinMurris. Email: karin.murris@uct.ac.za

Rose-Anne Reynolds is a doctoral candidate in the School of Education, University of Cape Town. She holds an MEd in applied language and literacy studies. Rose-Anne is a guest lecturer at the University of Cape Town for postgraduate certificate in education (PGCE) foundation phase students. Her current research interests include philosophy with children, the philosophy of child and childhood, and critical posthumanism. She is co-researcher in the Decolonising Early Childhood Discourses research project, funded by the South African National Research Foundation (NRF). Email: rlawrencereynolds@icloud.com
\end{abstract}

Joanne Peers is the head of inclusive support at Pinelands North Primary School, a public school in Cape Town. She is passionate about inclusion and disrupting the definitive notion of quality education. Joanne is a guest lecturer at the University of Cape Town for PGCE foundation phase students and currently completing her master's in education. She is co-researcher in the Decolonising Early Childhood Discourses research project, funded by the South African National Research Foundation (NRF). Email: joannepeers@ gmail.com

In this paper, we give a flavour of how, against the odds, Reggio-Emilia-inspired pedagogical documentation can work in reconceptualizing environmental education, reconfiguring child subjectivity and provoking an ontological shift from autopoiesis to sympoiesis in teacher education. Working posthuman(e)ly and transdisciplinarily across three foundation phase teacher education courses at a university in South Africa, we situate our teaching within current environmental precarities. We show how we stirred up trouble in and outside our university classroom and provoked our students to "make kin" with children, each other, other animals, and the more-than-human, but also to stay with the trouble, that is, to learn to be truly present in colonized spaces.

Key words: posthuman child; Reggio Emilia; autopoiesis; sympoiesis; environmental education; teacher education

\section{Discriminatory Animal:Human and Child:Adult Relations}

The work reported on in this paper involved three lecturers, all teaching the postgraduate certificate in education (PGCE) foundation phase in the School of Education, University of Cape Town. Over a period of six weeks (September-November 2017) Karin Murris, Rose-Anne Reynolds, and Joanne Peers planned their lectures together by regularly returning to the shared documentation in a Google.doc folder (audio and video tapes, photos, field notes, lesson preparation, our comments, etc.). Our students are be(com)ing foundation phase (5- to 9-year-olds in South Africa) teachers, and we show, mainly through visual images, how one picturebook can be used as a provocation for an e/ mergent curriculum in teacher education. Central in our assemblage is the changed relationality among human, subhuman, and more-than-human that should be at the heart of environmental education in the Anthropocene, and how this de/colonizing shift is brought into existence through collaborative Reggio-Emilia-inspired pedagogical documentation across three university courses. In particular, we focus on discriminatory animal:human and child:adult relations in segregated 
and enclosed spaces for children, adults, animals, and plants that are regulated through various inside/outside binaries that include and exclude, keeping the "other" at a distance. Schools, zoos, aquariums, botanical gardens, etc., are colonizing material-discursive spaces. These spaces assume nonegalitarian power relations between adult and child, humans and animals, and humans and plants.

To move beyond colonizing ontological relationality in-between humans of a certain age, race, gender, or class (and where they intra-sect) and between humans and more-than-humans, students need to be able take up an activist position seeking material and social transformation. Moving beyond notions of individual flourishing to multispecies flourishing is provoked through our use of picturebooks. We show how they are central to our innovative, philosophical work and, as material-discursive bodies, have brought new posthuman practices into being. Joanna Haynes and Karin Murris argue that contemporary picturebooks are post-age philosophical texts (Haynes \& Murris, 2012, 2017). They can constitute an e/mergent curriculum in schools as well as teacher education, and through an assemblage of mainly visual images we offer a modest imaginary of how we can-against the oddsteach differently in teacher education. In this paper we show how Julia Donaldson and Alex Scheffler's picturebook The Stickman (2008) provoked a project that embraced a nonrepresentational, rhizomatic exploration of concepts across three university courses, rather than using a transmission approach of giving fixed definitions of concepts.

\section{Human Exceptionalism}

To design and teach a posthuman teacher education curriculum in South Africa is challenging, for various, entangled reasons: the hegemonic developmental orientation of childhood education in higher education institutions, student teachers' own expectations of what amounts to a good education based on their own experiences of schooling, and the government's solutions to the current educational "crisis" (very low scores on international benchmark tests in mathematics and literacy) by introducing a new revised national curriculum: The Curriculum and Assessment Policy Statement [CAPS]. Since CAPS, teachers are under pressure to work with standardized national workbooks, including highly prescribed, specified, sequenced and paced guidance regarding the content that should be taught in schools with scripted lessons and worksheets. These interventions by the government reinforce the already existing focus in teacher education on strengthening the teaching of school subjects (mathematics and literacy) in their programs. Less value is attached to the subject of life skills in the foundation phase, which includes a mixed bag of, for example, the natural and social sciences, the creative arts, and physical exercise. Although not explicitly mentioned, environmental education is part of life skills and is theoretically framed by the human-(child)centered drive to reach the global sustainable development goals (SDG) and focuses on children's rights and their holistic development based on scientific evidence (Jamieson, Berry, \& Lake, 2017). So the official and hidden curriculum of South African schools is human centered. Like elsewhere, one of the aims of education is to socialize learners (and student teachers) into particular kinds of relationships that assume human exceptionalism. The concept "family" needs to be taught as part of life skills.

\section{Reconfiguring Relationality With the Subhuman and the More-Than-Human}

Fields as diverse as, for example, environmental humanities, the performative arts, cultural theory, education, organizational studies, critical geography, architecture, anthropology, political theory, childhood studies, and literary and literacy studies are now questioning human-centered figurations of the subject. Some argue that anthropocentrism and a focus on identity rather than difference is the main reason for present struggles with respect to race, gender, class, and the environmental problems in the controversially termed geological period of the Anthropocene ${ }^{1}$ in which we now live. Critical biologist and feminist philosopher Donna Haraway (2016) explains our current predicament passionately: 
These times called the Anthropocene are times of multispecies, including human, urgency: of great mass death and extinction; of onrushing disasters, whose unpredictable specificities are foolishly taken as unknowability itself; of refusing to know and to cultivate the capacity of responseability; of refusing to be present in and to onrushing catastrophe in time; of unprecedented looking away. (p. 35)

Haraway's writings include a passionate plea to cultivate "response-ability" and to resist "looking away" at our present time of "The Great Dithering" (2016, pp. 144-145). Our task, she urges, is not only to stir up trouble and "to make kin in lines of inventive connection as a practice of learning to live and die well with each other in a thick present," but also to stay with the trouble, that is, "to learn to be truly present ... as mortal critters entwined in myriad unfinished configurations of places, times, matters, meanings" (p. 1).

A plethora of terms has emerged that describe this "new" (for Western thinkers) philosophical orientation with implications for ethics: posthumanism, new materialism, vital materialism, relational materialism, sociomaterialism, object-orientated ontology, and so forth. There are more or less subtle differences among these philosophies. Our own inspiration for doing education differently is inspired mainly by the complex critical posthumanism developed by Haraway, Karen Barad, and Rosi Braidotti (who, in turn, draws heavily on Gilles Deleuze and Felix Guattari, who also in turn have developed their ideas in dialogue with the writings of Western philosophers Plato, Leibniz, Kant, Nietzsche, and especially Spinoza).

Although Haraway (2016) prefers the term "compostist" (p. 101) to posthumanist, her writings have been and still are very influential on the development of critical posthumanism, especially Karen Barad's influential strand of posthumanism. Haraway makes a useful distinction between seeing human animals as autopoietic systems and sympoietic systems (p. 176, note 13). In the former, humans have "self-produced binaries," they are "organizationally closed," "autonomous units," centrally controlled (e.g., through a human will or intellect), orientated around growth and development with "evolution between systems," and are "predictable" (p. 176, note 13). In contrast, sympoietic systems lack boundaries, are "complex amorphous entities," have "distributed control" with an "evolution within systems", and are "unpredictable" (p. 176, note 13). Haraway explains:

Sympoiesis is a simple word; it means "making-with." Nothing makes itself; nothing is really autopoietic or self-organizing. In the words of the Inupiat computer "world game," earthlings are never alone. That is the radical implication of sympoiesis. Sympoiesis is a word proper to complex, dynamic, responsive, situated, historical systems. It is a word for worlding-with, in company. (p. 58, italics in original)

Earthlings are "never alone." Theorizing subjectivity as an existential event is a paradigmatic shift from the discursive to the material-discursive and expresses a relational posthuman ontology salient for multispecies flourishing. The ontological fact that earthlings are "never alone" means that teachers are always part of, and situated in (as Haraway points out), complex, dynamic, historical, and responsive systems that are both material and discursive at the very same time. Teaching and learning are, therefore, "worlding-with" practices that disrupt power-producing Western humanist binaries, such as mind/body, culture/nature, cognition/emotion, theory/practice, and adult/ child, because categories that involve binaries, such as "subjects, objects, kinds, races, species, genres, and genders" are all products of relationships "between" significant others (Haraway, 2003, pp. 6-7). Similarly, Barad's neologism intra-action at the heart of her agential realism also emphasizes an ontological shift in how humans and morethan-humans relate with and influence each other (Barad, 2007, 2013). Intra-action is different from interaction in that nature and culture are never pure, are never unaffected by each other, but are always in relation-a sympoietic system for Haraway; an "entanglement” for Barad; and an "assemblage” for Deleuze. 


\section{Staying With the Trouble: Reggio Emilia and Philosophy With Children}

Key to our de/colonizing ${ }^{2}$ work is the use of Reggio Emilia and Philosophy for Children (P4C) as intra-active intragenerational pedagogies (Murris, 2016, 2017). It involves wondering about the established meanings of concepts through philosophical questioning and provoking projects (progettazione ${ }^{3}$ ) by taking the concepts that emerge in philosophical inquiries further into other intra-ventions through pedagogical documentation. This type of documentation demands that teachers are response-able for their observations, descriptions, interpretations, and explanations and dare to see the ambiguities (Dahlberg, Moss, \& Pence, 2013, p. 155)—always selective, partial, contextual, and situated. A willingness to be open to surprises and the unexpected is key. The documentation brings into the world a material-discursive expression of students' learning and their intra-action with more-thanhuman things, thought, affect, concepts, and environment (Edwards, 1995).

The pedagogical documentation of our teaching contains many images of the students' work, of them working together, sometimes on their own, often in small groups, and regularly as a whole class. The constant reworking of the documentation is a form of listening through annotated visualization of selected events in class, bringing energies and forces to the project work that open up new possibilities (Olsson, 2009, p. 41). In that sense, the posthuman pedagogy reworks the past across spacetime (Barad, 2007, 2014) as re-turning changes the in-between of what is documented and how it is "read" and the infinite possibilities created in this way. The conceptual focus seemed the key to such a dynamic, evolving curriculum: provoking new thoughts, emotions, sensations, and perceptions.

In particular, we focused at the end of last year on the concepts "family" and "family tree" - generated partly by the students themselves. Resisting the temptation to define these concepts and treat them as representations of an independently existing reality "out there," we worked with them transversally, that is, they cut across the binaries of the objective (nature) and the subjective (culture). They not only stirred our minds, but also struck our bodies (Massumi, 2015, p. x). They constrain as well as express desire and freedom. Switching "languages" transmodally thickened the sedimented understandings of concepts and the relationships they are always part of (in our teaching this was, for example, stick-tree-wood-land-conservation-laws-colonization-country-earthuniverse-the-humans-who-created-the-concept).

\section{Transmodality}

We regard transmodality as the creation of new understandings of concepts through the switching of one hundred languages (and a thousand more) to project forward as part of a process of intra-action in-between human and nonhuman bodies (which is different from self-expression). The famous metaphor of "the hundred languages" is from a poem written by Loris Malaguzzi. A powerful critique of the privileging of the dominant two languages in (higher) education, reading and writing, the metaphor refers at one (practical) level to the introduction of materialdiscursive tools for meaning making in schools, such as visual arts, physical movement, video, digital cameras, augmented realities, and computers. At a symbolic level, the hundred languages are, as Carlina Rinaldi (2006) puts it: a "metaphor for crediting children and adults with a hundred, a thousand creative and communicative potentials" (p. 175). Before showing how we have used the concept family transmodally, adopting the hundred languages of Reggio Emilia we first explore further why human-centered figurations of the subject are troublesome.

\section{Posthuman Child and Learning About Posthumanism Experientially}

Posthuman teaching is a radical shift from a Cartesian substance ontology to an intra-active relational ontology. It moves discussions about relationality from the sociological to the ontological-the so-called ontological or material 
turn in the history of ideas. This turn sits uncomfortably with pedagogies informed by scientific realism, social constructivism, postmodernism, or poststructuralism which all assume that linguistic or other semiotic systems mediate between nature and culture (Murris, 2016, chapter 3). The power of these systems has been not only substantial but also "substantializing," allowing linguistic structure to determine our understanding of the world (Barad, 2007, p. 133). Take, for example, the standardized educational practice of giving definitions of concepts to capture the essence or meaning of concepts, also in higher education, including attempts to define what child is by nature. Curiously, neither Barad nor Braidotti nor Haraway explicitly refers to adult:child relationality.

However, our transmodal work with student teachers across three preservice education courses (Childhood Studies, Life Skills, and Special Studies) in the University of Cape Town's School of Education shows how the ontological shift from autopoiesis to sympoiesis denaturalizes child and childhood. Students' material-discursive expressions evidence a philosophical distancing from the figuration of the developmental child of psychology (child as ' $i$ '), the self-contained, autonomous child of the children's rights discourse (child as 'I'), and the child-in-socioculturalcontext of sociology (child as 'ii') (Murris, 2016). We start with the neologism child as 'i' (Figures 1 and 2).

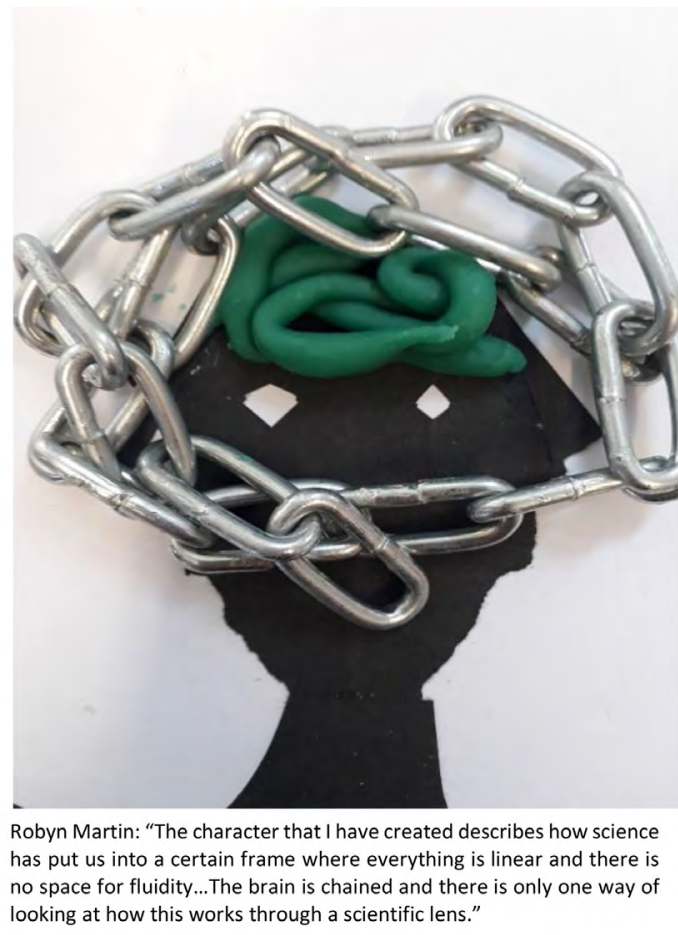

Figure 1. Child as 'i’ by Robyn Martin.
Jacqueline Graham:

The character I have created for child as ' $i$ ' depicts an adult and child. The adult is positioned above the child, showing an authoritarian and dominant view of adult over child. The vertical orientation of the picture further reinforces this adult/child Western binary thinking. The arrow beginning with child points vertically up towards adult - literally 'growing up'; positioning adult as the desired outcome of this scientific process of maturation. The straight line of the arrow reinforces the linear, and narrow-thinking of the child as ' $i$ ' as an underdeveloped human and highlights the problem of conflating physical and cognitive maturation.

Notably, as seen in the character, the adult has what the child has yet to attain from a very scientific, humanist approach as represented by the fingerprint on the child a symbol for assessing identity based on genetic science. The adult is represented with arms and legs to symbolise his freedom of mobility and autonomy; something the child is represented without. The child is thus immobile, vulnerable and entirely dependent on the adult.

Importantly, the adult also has a mouth, representing his freedom of expression; something the child is represented without. This notion of child, views the child's mind as immature and therefore his/her thoughts or opinions are seen as less important and lacking in rational thought, than those of adults. This idea is reinforced by the age-old proverb 'children should be seen and not heard'. The adult is purposefully discussed first and is positioned as standing in relating to the child who is laying down in this discursive to overshadow the child; as indicated by the belittlement of child using lowercase ' $i$ ' in favour of prioritising the adult as capital ' $P$ '...placing the teacher as authoritarian holder of knowledge.

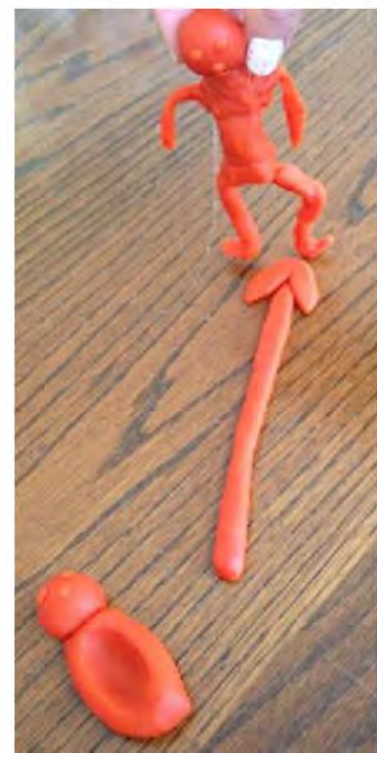

Figure 2. Child as 'i’ by Jacqueline Graham. 
When we started teaching the three preservice teacher education courses we draw on in this paper, we began by returning to their feedback halfway through their second teaching practice (TP). Karin teaches Childhood Studies. She had put large sheets of flipchart paper on tables in the middle of the room and each student drew, wrote, and used playdough and other materials. They then walked around the large rectangle of paper-tables and intra-acted (diffracted $^{4}$ ) with other students' expressions. After TP, our first lecture started with revisiting the large sheets of paper and intra-acting with the visual images and writings on it (Figure 3).

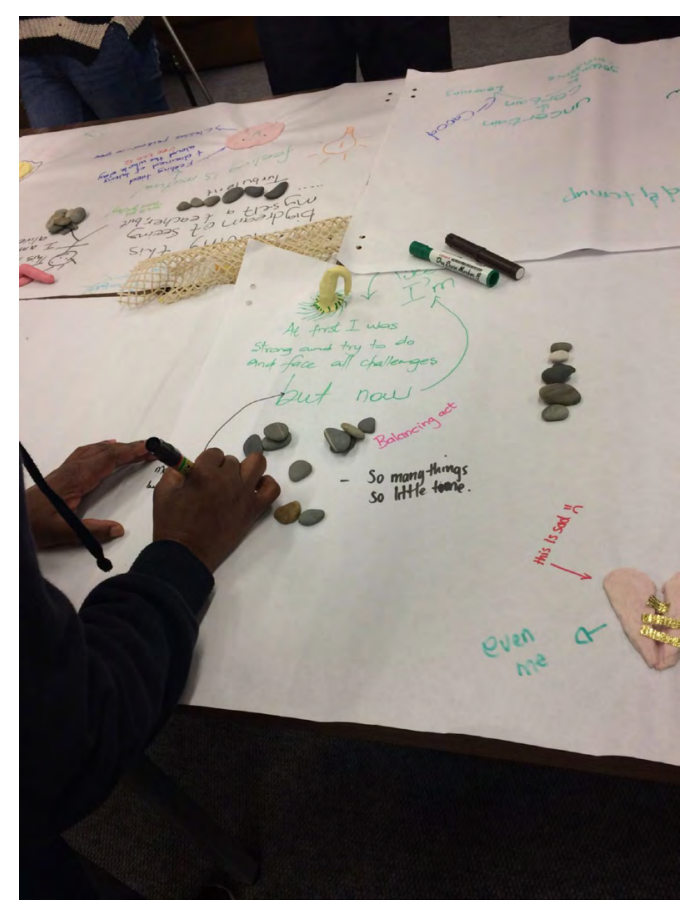

Figure 3. A map of students' teaching practice experiences.

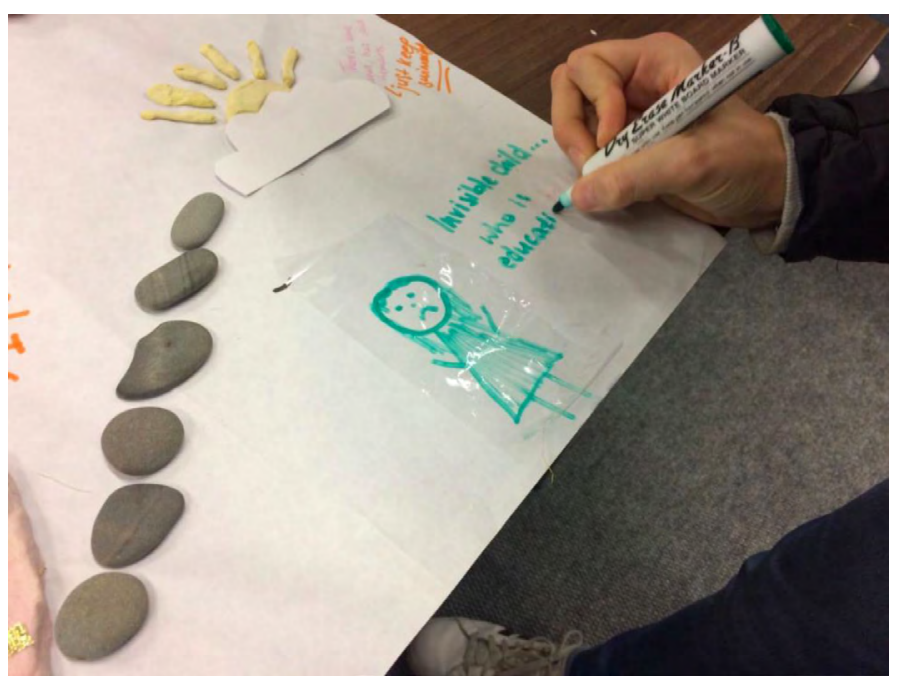

Figure 4. Tannagh Pfotenhauer's invisible child ... Who is education for?

We had previously discussed the impact of these pages and the effect they had on them. The students expressed deep disappointment in what it means to be a teacher in practice, and there was a heavy atmosphere in the university classroom. Many felt invisible in their school as student teachers. Not really being taken seriously themselves, they also expressed concern about the children, who were not learning much and were often shouted at, or worse. There were deep sighs and much silence. One student wrote and drew a powerful image: Invisible child ... Who is education for? (Figure 4), with transparent plastic expressing the lack of visibility and respect for children in South African schools.

Our task as teacher educators seems overwhelming in teaching our students how we can respect children as knowledge producers by introducing a different relationality that does justice, not only to the subhuman, but also to other animals and the more-than-human.

In her childhood studies course, Karin asked the students to create narrative characters of her neologisms child as $i$, I, ii, and $i_{i}{ }^{5}$. Kieran Egan (2006, p. 3) argues that successful teaching depends on engaging feelings. One cognitive tool he suggests is to create characters (from numbers, commas, phonemes, etc.) and stories with them in order to-as Egan puts it-make "within yourself an emotional connection with the topic" (Egan, 2006, p. 3, emphasis in original). Personifying characters and making stories helps in being affected by concepts. Karin speculated that it might also help the students engage with different figurations of child and childhood. It was striking that the students struggled with the "child as I" character. They could not quite imagine what it would be like for children in schools to be treated, for example, as having participation rights. Tristan Barrett created the following QR code to express the "child as I" character, which although "competent," is still a developmental one with adulthood as ideal. 
Karin also invited the students to read out loud in a circle and discuss Loris Malaguzzi's Your Image of the Child: Where Teaching Begins (1994). This powerful article by the founder of the Reggio Emilia approach to education seemed the right choice in the context of their disturbing teaching practice experiences. What stood out for the students as an expression of "child as iii" (posthuman child) was this:

We need to define the role of the adult, not as a transmitter but as a creator of relationships - relationships not only between people but also between things, between thoughts, with the environment. It's like we need to create a typical New York traffic jam in the school. (Malaguzzi, 1994, n.p.)

This discussion, in turn, inspired student teacher Tannagh to express child as 'iii' as shown in Figure 6.

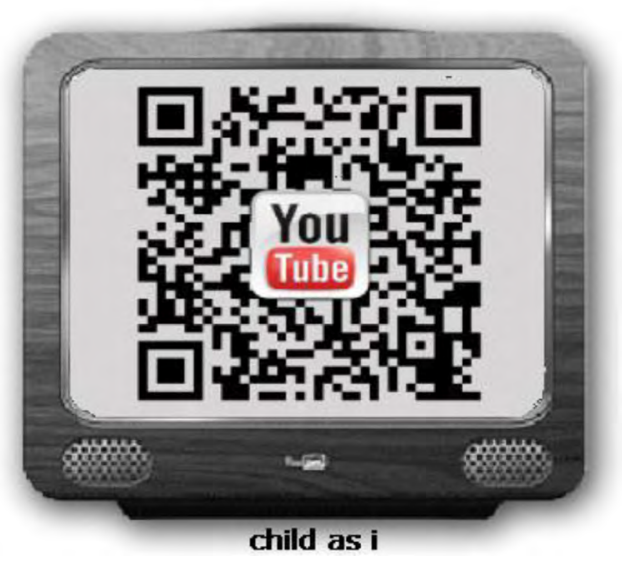

Figure 5. Child as I: The competent child with children's rights, by Tristan Barrett.

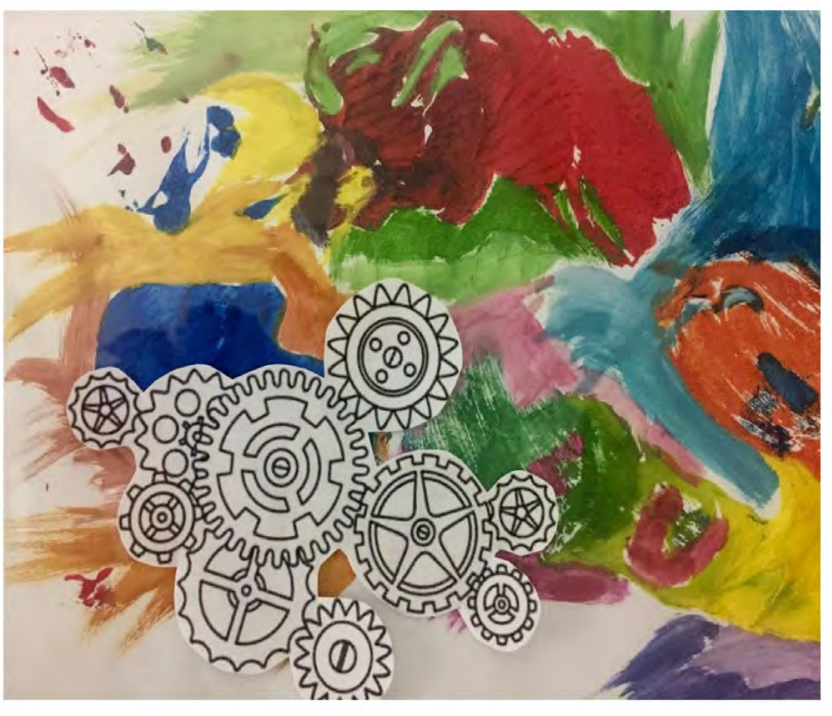

Tannagh Pfotenhauer:

My image reinforces the idea that the child is constituted by forces, whose measuring and controlling machines are entwined. The idea is that the child is constantly emerging, producing, and becoming, as a part of the world, in relation to everything that exists around them. The posthuman child view puts a focus on the assemblages of flows and forces in each moment. I have included cogs of a machine to represent the continuous producing nature of the posthumanist perspective, but these machines are a part of everything else, all intra-acting together. The mish-mash of colours show how clear boundaries are lost in this intra-active process, leading to a view of the child as full of potential in this current moment, bringing with them, their lived experiences and relations with the world around them.

I believe that the idea of the child as 'iii' has the potential to bring about meaningmaking in my future classroom, with the notion that everything is constantly flowing in between everything else. This view opens up possibilities of rethinking subjectivity, which is so vital in education. As a teacher, I need to understand that meaning is made through co-constructive processes between organisms. Through deconstructing childhood, we, as teachers, can become more aware of the 'eyes' or 'glasses' we view child through. We cannot possibly take these away, but we can become more aware of them. Through this, we can try to understand the idea that the way in which a child comes into the world is shaped by the actions of others (human and nonhuman).

Figure 6. Child as 'iii' by Tannagh Pfotenhauer.
Student teacher Nadia Woodward beautifully expressed her entire interconnected family: "child as i, I, ii, and iii" (Figure 7).

With posthumanism as our navigational tool, we use the concept child, not to depict a singular entity in the world of competencies, voice, agency, and so on, but to express human and more-than-human intra-active relationality. Individuals materialize and come into being through relationships, and so does meaning. The neologism child as iii (Murris, 2016) expresses posthuman child: a subject (an inhuman becoming) that is part of the world and not an object in space and time (as container concepts). Importantly, it does not follow, as is often assumed, that the subject does not matter epistemically or ethically. As Liselott Olsson (2009) strikingly puts it,

what is talked about is in no way whatsoever a "dead" subject. On the contrary the ideas of subjectivity that are put forward ... concern a subject that is more alive than ever. But it is also a subject that is constantly in the making, a becoming subject, and this subject is much more than an individual subject; it is a totally unique and singular subject that is never repeatable, not even to itself. (p. 127)

The ontological shift in subjectivity also means in a sense that "adult has become child ... a being who is incomplete, always on-the-way, who is never finished developing" (Kennedy 2006, p. 10). This postdevelopmental shift in 

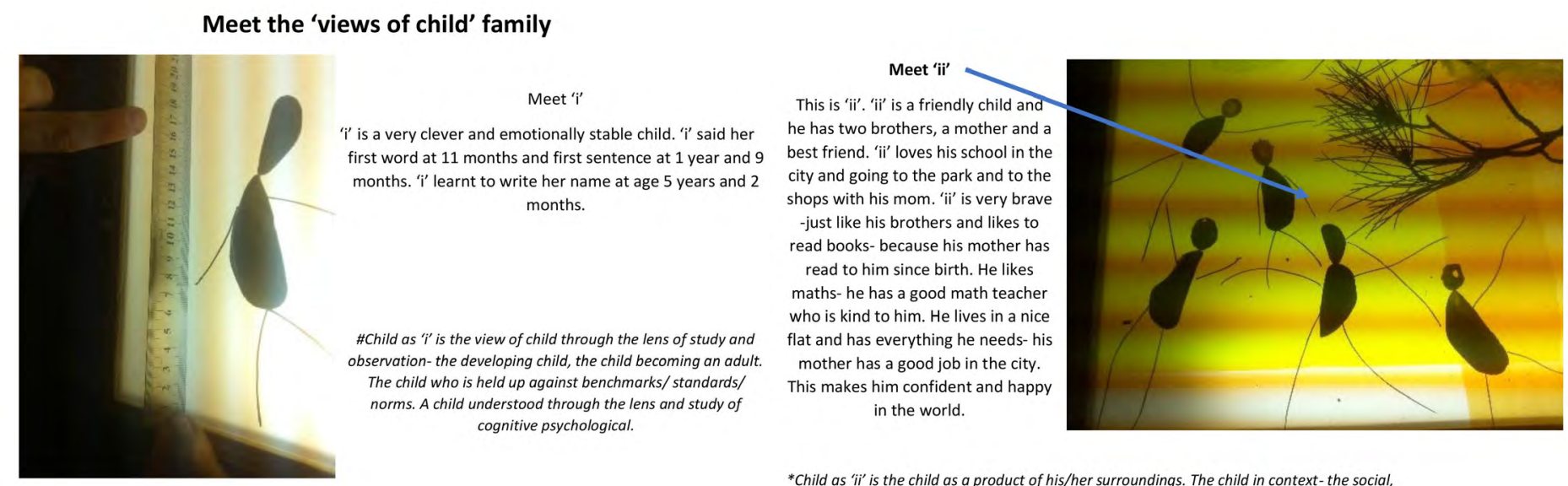

\#Child as ' $i$ ' is the view of child through the lens of study and observation- the developing child, the child becoming an adult. The child who is held up against benchmarks/standards/ norms. A child understood through the lens and study of cognitive psychological.

*Child as 'ii' is the child as a product of his/her surroundings. The child in context- the social, political context within which we find child determines our view of such child
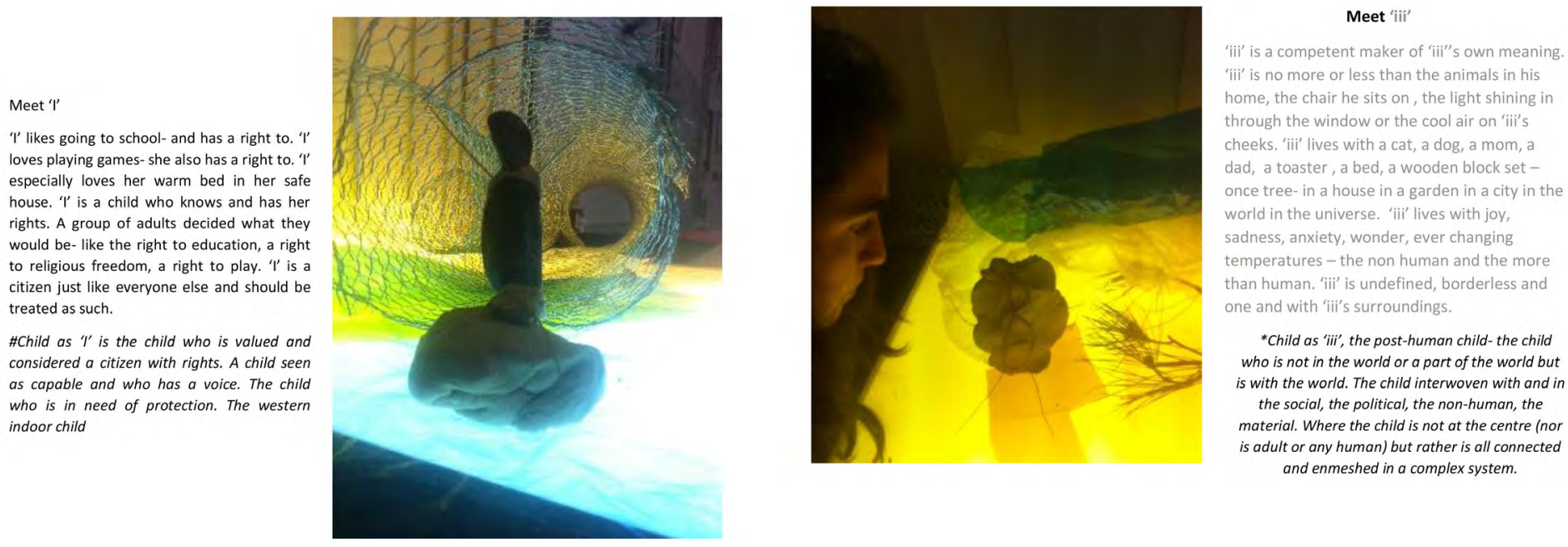

Figure 7. Nadia Woodward's figurations of child as $i, I$, ii, and iii using clay and a light box.

child subjectivity opens up further explorations with our students about posthuman subjectivity more generally. Posthumanism not only disrupts the adult:child binary, but profoundly democratizes the playing field in many directions - nothing is considered to stand outside or above or to take a true, privileged, transcendental position, and this is critical for de/colonizing environmental education in the Anthropocene. It understands the human body of any age as an unbounded organism that exists in an entangled network of human and nonhuman forces, opening up a nonhierarchical kind of being and knowing by queering human-made categories (e.g., nature/ culture) that include and exclude. Early childhood educator Fikile Nxumalo (2014) points out that Indigenous knowledges have for millennia taught that "human subjectivities are inseparable from their more-than-human relations and responsibilities" (p. 54).

Both critical posthumanism and Indigenous knowledge systems encourage educators philosophically and practically to engage with more robust and complex accounts of the relationality involved in pedagogical encounters, reconfiguring adult-child and animal-human relationships in schools, the material world, the environment, and the relationship between theory and practice (Olsson, 2009; Lenz Taguchi, 2010; Murris, 2016; Pacini-Ketchabaw, Nxumalo, Kocher, Elliot, \& Sanchez, 2015; Pedersen, 2016; Snaza \& Weaver, 2015; Taylor, 2013; Taylor \& Hughes, 2016). However, despite the urgency of a shift to a relational ontology for sustainability education (Malone, Truong, \& Gray, 2017), the nitty-gritty of how to prepare student teachers in higher education for alternatives to hegemonic 
Western binary logic in our understandings of the world is slow coming forward.

For student teachers to embrace practices of staying with and stirring up trouble and making kin in their own future classrooms, they need to experience different ways of relating, not only to the subhuman (child), but also to other animals and the more-than-human. They also need to experience themselves, as students, how their own teachers plan for teaching differently, rhizomatically ${ }^{6}$, and collaboratively. These experiences are not holistic, but dis/embodied in the sense that they are "transindividual." Bodies are not bounded by a skin as units in space and time, but are in/determinate subjects and produced involving contradiction and multiplicity (hence: dis/ embodied). Posthuman pedagogies assume "nomadic subjects" (Braidotti, 2006, 2013), selves who are not only epistemologically homeless, but also dis/continuously (Barad, 2014) becoming.

The philosophical shift in subjectivity poses profound challenges in teacher education as student teachers need strong systems of support and mentoring through carefully designed preservice education. Considering our program is primarily designed as a quick preparation for becoming a teacher, how does one teacher-educate posthuman(e)ly? In what follows, we share one example of our collaborative work.

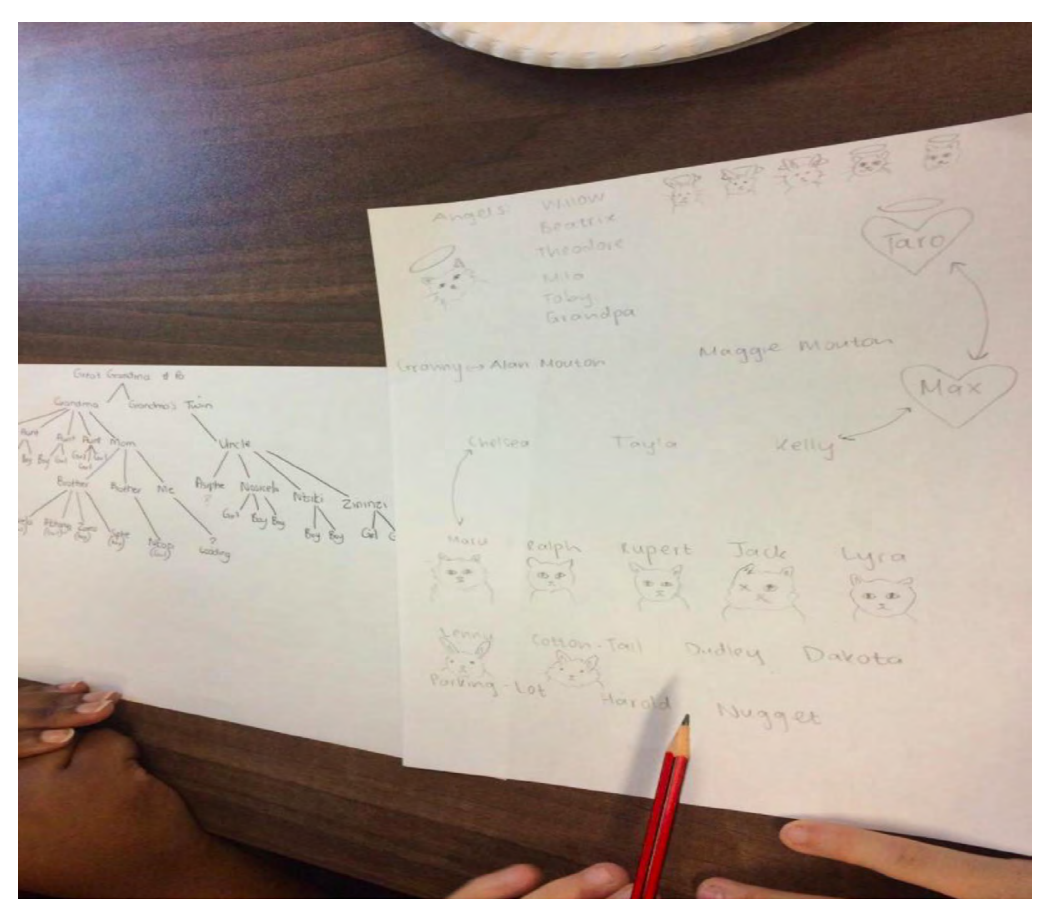

Figure 8. Two students' family trees, one including pet animals.

\section{The Stickman and the Family (Tree)}

The Stickman (2008) is an illustrated poem about the toy of the gruffalo's child-a character in another picturebook by Julia Donaldson and Alex Scheffler-who gets involved in a terrifying journey when he takes a jog away from his family tree, inhabited by "Stick Lady Love and their stick children three." Before using the picturebook, Karin had asked each student to draw their own family tree. Some had drawn hierarchical ones, and one student had made a rhizomatic drawing. We explored in depth the reasons for who or what was on their tree (are genetic "blood" lines necessary?). Some students had included their pet animals (see Figure 8).

When intra-acting with the pedagogical documentation, we noticed that the concepts family, belonging, and alive/dead kept returning in our work with the students. To thicken the sedimented understandings (Barad, 2007) of these concepts, Karin offered students the opportunity to intra-act with the embedded augmented reality iSolar System book (Carlton Books, 2013). Through a downloaded app on their smartphone, the planets come alive and circle around each other (see Figure 8). A conceptual connection was made with the Stickman's belonging to his family tree, and Karin stirred up trouble by asking "Is the earth part of a family?"

The students expressed deep puzzlement about the hierarchy between human and nonhuman, about anthropomorphism by prioritizing human needs over animals and objects, and powerful links were made with the field trips Rose-Anne organized as part of the course Special Studies ${ }^{7}$ to the Two Oceans Aquarium and Arderne Gardens in Cape Town. We used the outings to the aquarium and a botanical garden to further explore, 
posthumanly, the question, "How does the concept of family work?"

On arrival at the aquarium, we were struck by a poster welcoming visitors with a hermit crab saying, "Join the family" (see Figure 10). By implication, we were not already members of this family.

Joining this family would involve a hefty financial transaction, and the students were troubled by how expensive it was to visit the aquarium, which meant it excluded groups of people who could not afford to pay the entrance or joining fees, which in turn would then impact who could be a part of the "family." One student asked, "Is the aquarium a private school?" and this led to a discussion about inclusion and exclusion and access to resources. During apartheid, resources were deliberately limited and access to schooling was limited to specific groups of children and people. These inequalities still exist today in a two-tier education system.

The tanks in the aquarium are meant to be homes for the various sea creatures. Their material-discursive presence raised questions that stirred up trouble for our class of 21 student teachers. The tanks are designed for particular groupings of fish, so the aquarium ended up being a "family" with tanks as rooms with no interleading doors because all the tanks were separate, so which "family," therefore, was to be joined? After all, only humans could voluntarily join the family; the fish and sharks had no say in whether they wanted to be there or not. One student expressed her concern that the fish in the tanks had been removed from their larger families in the ocean to be available to be looked at by the aquarium visitors: "Fish in tanks are also part of a family-never thought of that before." Is family then a human concept, and how does the concept work to include and exclude? How does it prevent making kin with other animals and the more-than-human?

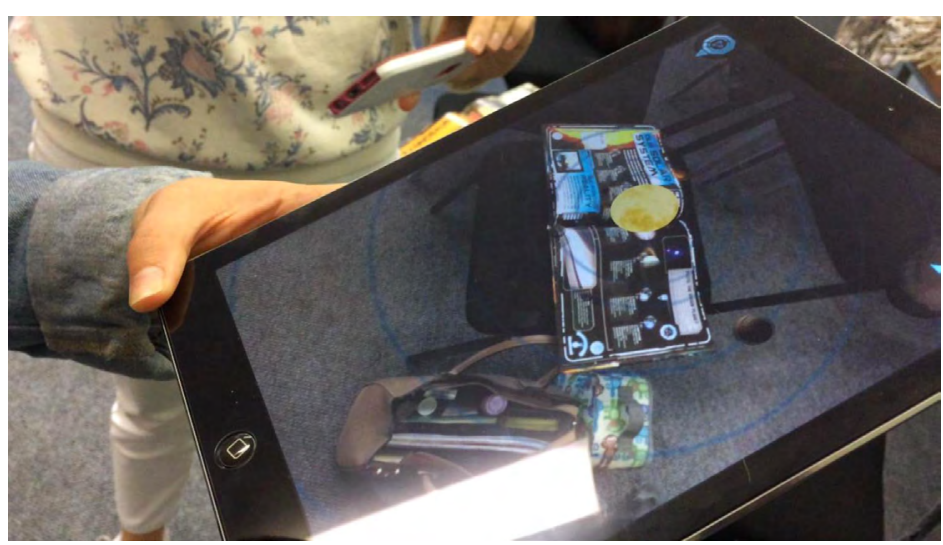

Figure 9. Planets coming alive in the iSolar System book.

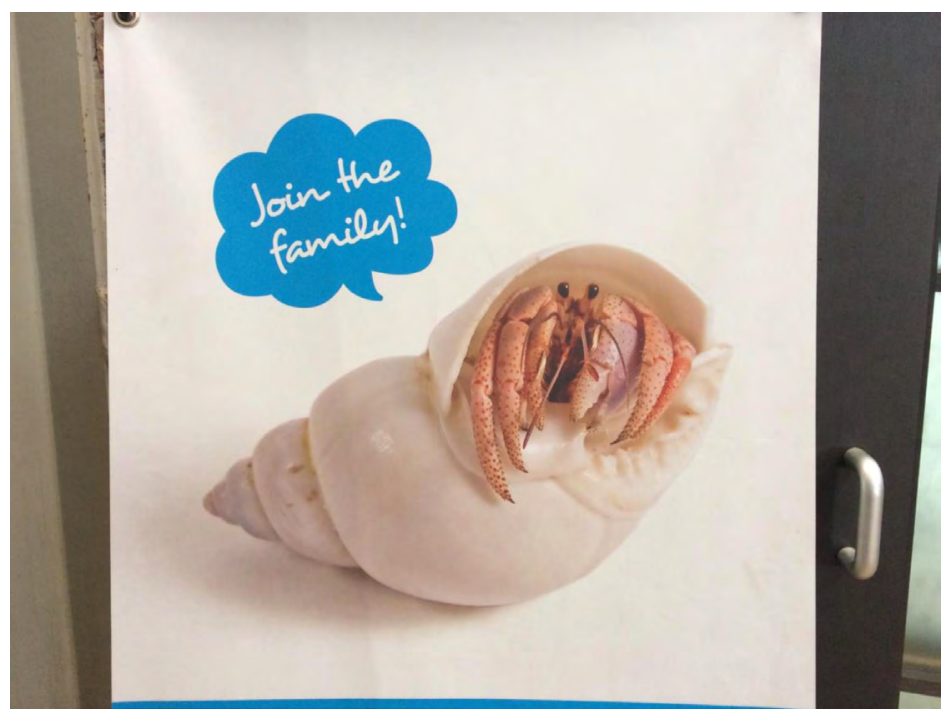

Figure 10. Poster at the Two Oceans Aquarium in Cape Town inviting visitors to become a family member.

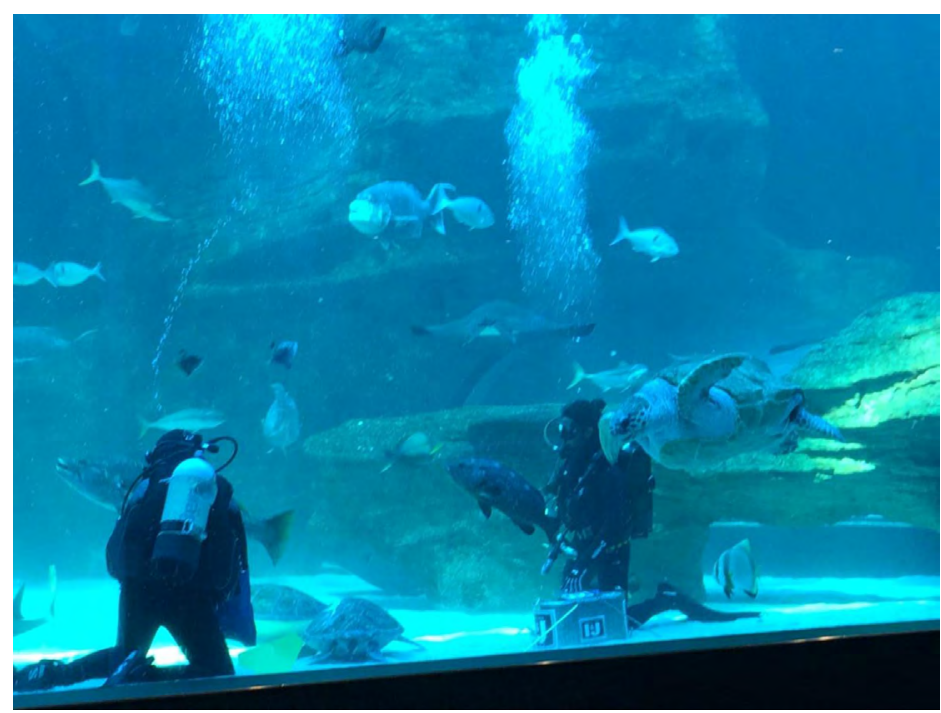

Figure 11. Divers feeding the obese turtle. 


\section{Animals on Life Support in the Aquarium}

On the day we were in the aquarium, there were a lot of schools visiting. In Figure 15, you can see how the educational intra-vention had been set up. The idea is for the children to sit still, be quiet, and listen to the presenter (with the mic), while the divers and different fish are on display in the tank behind them. This is the way fish and their lives are presented to the children. An ideal ocean-no destruction, no evidence of the harm humans inflict on the ocean-those messages are conveyed separately and differently. Here, the presenter recites a script about what he (or/and his line manager) thinks the humans and children want to and should know about the fish in the tank behind them. The children in the audience raise their hands to ask questions or to tell others what they already know or are experiencing as they watch the sea creatures in the tank. Most hands are not answered-the knowledge and knowing about the fish is firmly located in the adult human with the mic. Education here presupposes subjectivity as an autopoietic system with "selfproduced binaries" (Haraway, 2016, p. 58), positioning child as ' $i$ ' with a developmental orientation and

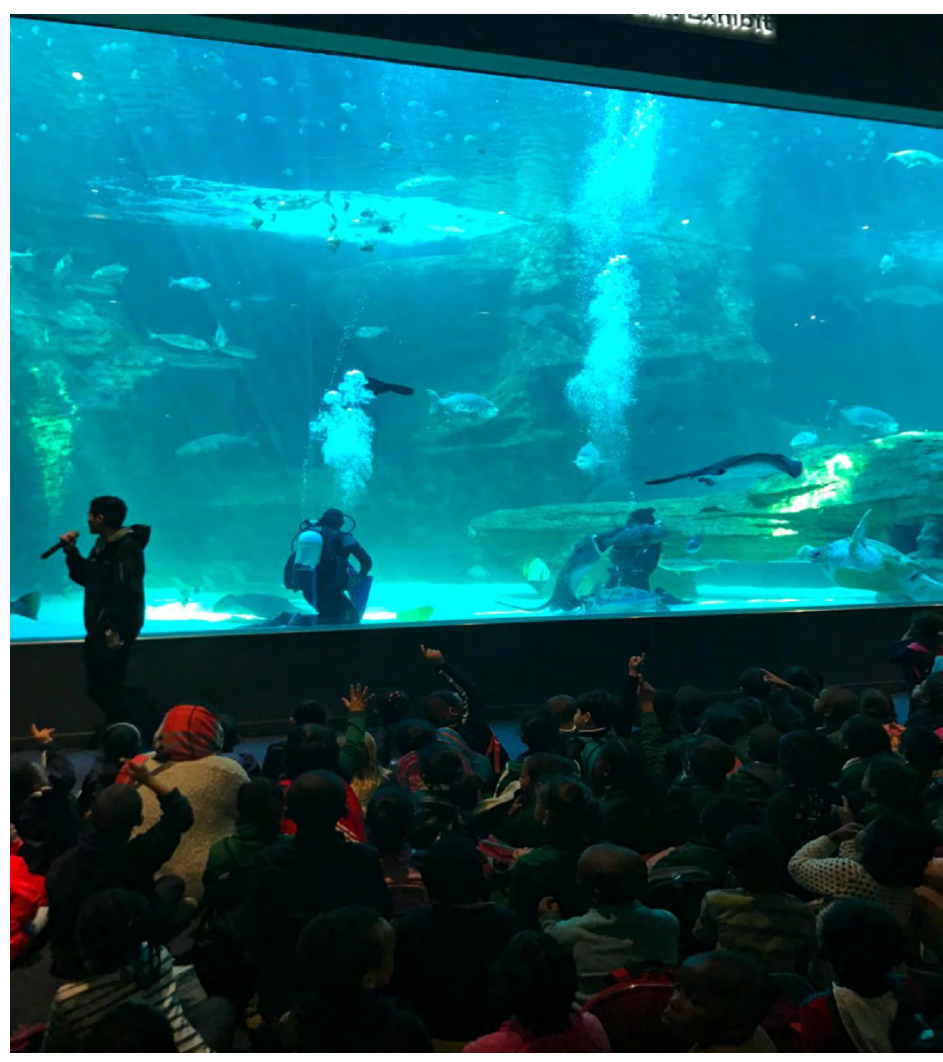

Figure 12. The biggest exhibit at the Two Oceans Aquarium in Cape Town. without surprises or opportunities for dis/embodied learning.

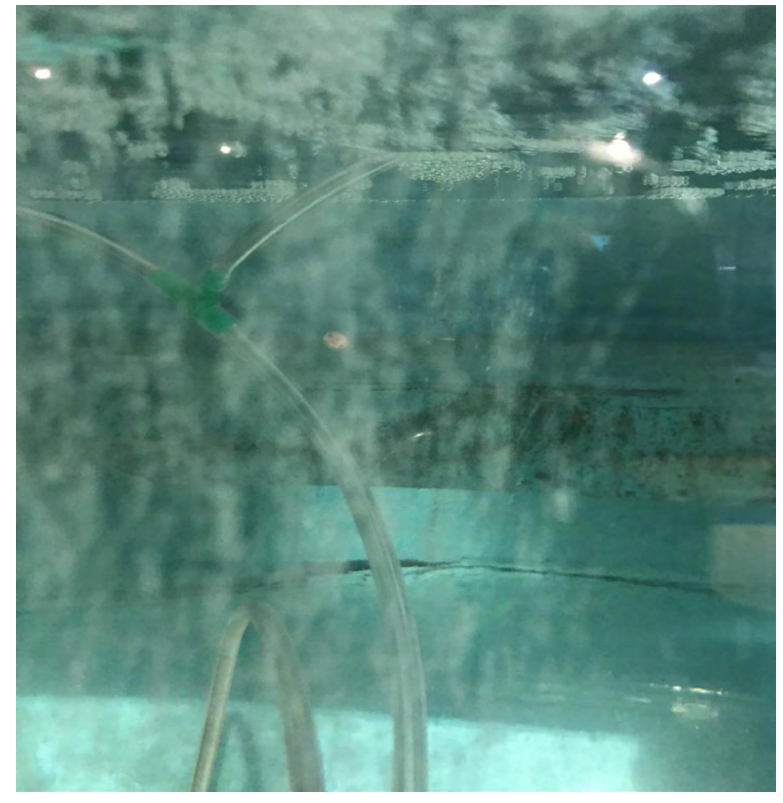

Figure 13. Tubes providing oxygen to the fish in a tank in the aquarium classroom.
As part of this event, the students asked: "Is it ethical to watch fish?" and "Are fish comfortable being watched by strangers?" These unexpected, complex, dynamic, responsive, and situated questions are part of learning as a sympoietic system-a "worlding-with, in company" and being "truly present" (Haraway, 2016, pp.1,58) in colonized spaces.

Rose-Anne was particularly struck by the advanced forms and use of technology necessary to keep the fish alive. In every tank, tubes were needed to pump oxygen to enable sea creatures to breathe and survive. It is a form of life support that would not be necessary if creatures had been left in the ocean. The fish are kept alive in these artificial conditions for the benefit of the human "family" who come to visit (see Figure 13). Not only are the fish kept alive by oxygen that filters into the tanks, but their food is given to them by the divers. Ironically, the environmental education leaflet at the aquarium promises visitors to connect "a wide audience with nature." But "nature" and "culture" always intra-act, are never "pure" or unaffected by each other. They are always entangled and part of a sympoietic system (Haraway, 2016). 


\section{Not Just Family as Defined by and Only for Humans}

One way to respond to Haraway's (2016) passionate plea to cultivate response-ability and to resist "looking away" at our present time of "The Great Dithering" (pp.144-145) is to move our primary place of learning and teaching to the outdoors. After returning to our documentation of the aquarium, we decided to visit Arderne Gardens a couple of weeks later with the aim of stirring up more trouble with the concept family tree. The choice of that particular botanical garden was deliberate: It is the home of alien trees and plants whose reason for being in the park is that they were "exotic" to South Africa. These trees do not "naturally" "belong" there. They are not part of the flora indigenous to South Africa and were planted by White settlers (the Arderne family).

One particular tree called the Moreton Bay Fig demanded our attention. It is one of the oldest exotic trees in South Africa (around 165 years old), but of course not as old as the indigenous trees. The tree was not background or context, but part of the reading: a reading-with, a thinking-with. We suggested to the students that they take up the invitation by the tree's huge roots on top of the soil, creating contained spaces, and read the picturebooks we had brought along in small groups to each other. These picturebooks all featured trees and forests. At the time, we had no idea that this fig tree is also interestingly called the "wedding tree" because so many couples have their wedding photos made in between the roots and in front of the tree.

Angela Webb, leaning against and supported by the giant roots, read Anthony Browne's Hansel and Gretel (2008) to fellow student teacher Zukile Ncube. Without being able to articulate it fully in words, we are struck by the materialdiscursive entanglement of Figure 14, making kin between

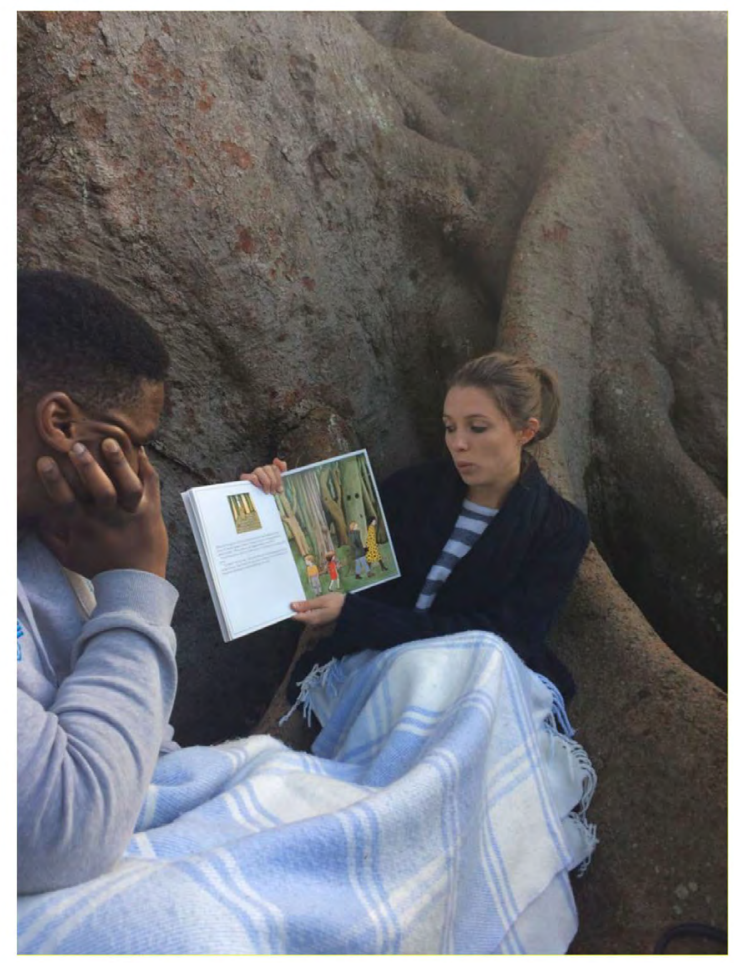

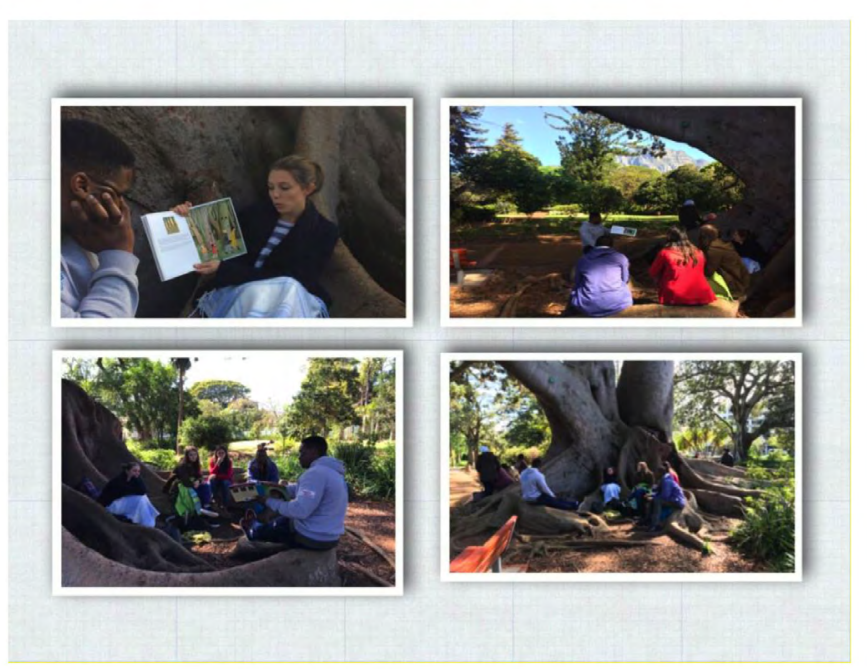

Figure 14. Student Angela Webb reading Anthony Browne's Hansel and Gretel to Zukile Ncube. human and nonhuman, transversing gender, race, class, and age: soil-paper-blanket-hands-concentration-texturestripes-blue-bark-bedtime-fairytale...

So how then do we think about family, and not just family as defined by and only for humans?

Our philosophical teaching disrupted the colonizing, power-producing, Western humanist binaries-the assumptions that picturebooks are only for children, that reading in educational institutions happens inside buildings, that a human family is more important than fish or tree families, and that these families cannot exist beyond human-created binaries. Our collaborative work with the students dis/continuously raised questions about what it means to belong to a family. 


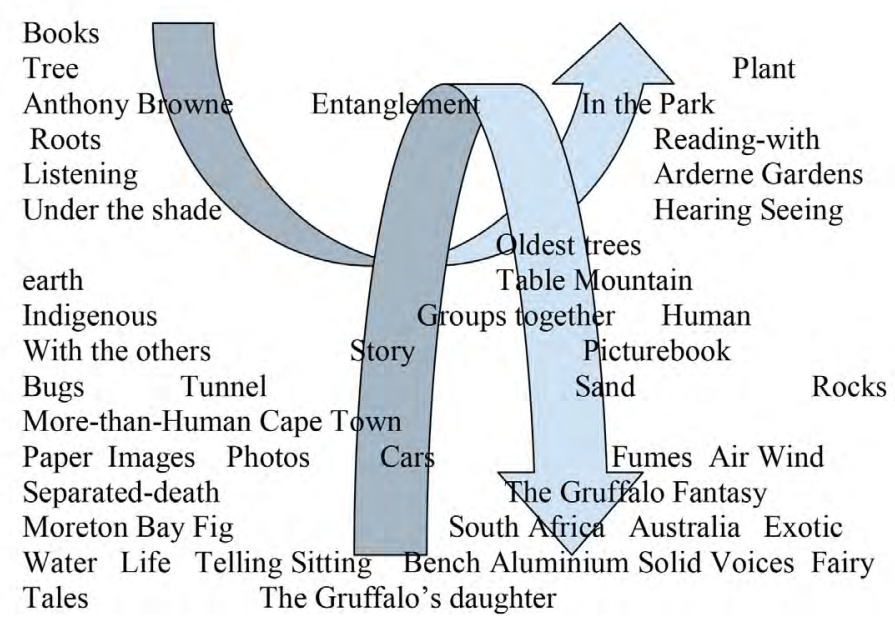

Figure 15. Entanglement of the human, subhuman, and more-than-human.
We "end" with powerful questions posed by Haraway (2016, p. 2), questions that will continue to stir up trouble in our teacher education program:

Making kin as oddkin rather than, or at least in addition to, godkin and genealogical and biogenetic family troubles important matters, like to whom one is actually responsible. Who lives and who dies, and how, in this kinship rather than that one? What shape is this kinship, where and whom do its lines connect and disconnect, and so what? What must be cut and what must be tied if multispecies flourishing on earth, including human and other-than-human beings in kinship, are to have a chance?

\section{Acknowledgements}

We would like to thank all the students of the PGCE Foundation Phase 2017 at the University of Cape Town for our inspiring journeying together and Angela Webb and Zukile Ncube for giving permission for the photos in Figure 14. In particular we would like to thank Tristan Barrett, Jacqueline Graham, Robyn Martin, Tannagh Pfotenhauer, and Nadia Woodward for their permission to publish parts of their formative assessments for Childhood Studies and Tristan for the QR code.

\section{Funding}

This writing is based on research supported by the National Research Foundation of South Africa [grant number 98992]. 


\section{References}

Barad, K. (2007). Meeting the universe halfway: Quantum physics and the entanglement of matter and meaning. Durham, NC: Duke University Press.

Barad, K. (2014). Diffracting diffraction: Cutting together-apart. Parallax, 20(3), 168-187.

Braidotti, R. (2006). Transpositions: On nomadic ethics. Cambridge, UK: Polity Press.

Braidotti, R. (2013). The posthuman. Cambridge, UK: Polity Press.

Browne, A. (1981). Hansel and Gretel. London, UK: Walker Books.

Carlton Books. (2013). iSolar System [application]. Retrieved from https://www.carltonbooks.co.uk/isolar-system-ar-hb.html

Deleuze, G., \& Guattari, F. (1987/2014). A thousand plateaus: Capitalism and schizophrenia (B. Massumi, Trans.). London, UK: Bloomsbury.

Donaldson, J., \& Scheffler, A. (2008). The stickman. London, UK: Alison Green Books.

Edwards, C. (1995). Democratic participation in a community of learners: Loris Malaguzzi's philosophy of education as relationship. Lecture prepared for an international seminar. University of Milano, October 16-17, 1995. Retrieved from http://digitalcommons.unl. edu/cgi/viewcontent.cgi?article=1014\&context=famconfacpub

Egan, E. (2006). Teaching literacy: Engaging the imagination of new readers and writers. Thousand Oaks, CA: Corwin Press.

Haraway, D. (2016). Staying with the trouble: Making kin in the Chthulucene. Durham, NC: Duke University Press.

Haynes, J., \& Murris, K. (2012). Picturebooks, pedagogy, and philosophy. New York, NY: Routledge.

Haynes, J., \& Murris, K. (2017). Intra-generational education: Imagining a post-age pedagogy. Educational Philosophy and Theory, 49(10), 971-983.

Jamieson, L., Berry, L., \& Lake, L. (2017). South African child gauge 2017. Cape Town, South Africa: Children’s Institute.

Kennedy, D. (2006). Changing conceptions of the child from the renaissance to post-modernity: A philosophy of childhood. New York, NY: Edwin Mellen Press.

Lenz Taguchi, H. (2010). Going beyond the theory/practice divide in early childhood education. London, UK: Routledge.

Lipman, M., Sharp, A. M., \& Oscanyan, F. S. (1977). Philosophy in the classroom (2 ${ }^{\text {nd }}$ ed.). Philadelphia, PA: Temple University Press.

Malaguzzi, L. (1994). Your image of the child: Where teaching begins. Exchange, 3(94).

Malone, K., Truong, S., \& T. Gray. (2017). Reimagining sustainability in precarious times. Singapore: Springer Nature.

Massumi, B. (2015). Politics of affect. Cambridge, UK: Polity Press.

Murris, K. (2016). The posthuman child: Educational transformation through philosophy with picturebooks. London, UK: Routledge.

Murris, K. (2017). Reading two rhizomatic pedagogies diffractively through one another: A Reggio inspired philosophy with children for the postdevelopmental child. Pedagogy, Culture, \& Society, 25(4), 531-550. doi: 10.1080/14681366.2017.1286681

Nxumalo, F. (2014). Unsettling encounters with "natural" places in early childhood education (Doctoral dissertation). Retrieved from https://dspace.library.uvic.ca/bitstream/handle/1828/5772/Nxumalo_Fikile_PhD_2014.pdf?sequence=1\&isAllowed=y

Olsson, L. M. (2009). Movement and experimentation in young children's learning: Deleuze and Guattari in early childhood education. London, UK: Routledge.

Pacini-Ketchabaw, V., Nxumalo, F., Kocher, L., Elliot, E., \& Sanchez, A. (2015). Journeys: Reconceptualizing early childhood practices through pedagogical narration. Toronto, ON: University of Toronto Press. 
Pedersen, H. (2016). Animals in schools: Processes and strategies in human-animal education. West Lafayette, IN: Purdue University Press.

Rinaldi, C. (2006). In dialogue with Reggio Emilia: Listening, researching, and learning. London, UK: Routledge.

Seghal, M. (2014). Diffractive propositions: Reading Alfred North Whitehead with Donna Haraway and Karen Barad. Parallax, 20(3), $188-201$.

Snaza, N., \& Weaver, J. A. (2015). Posthumanism and educational research. New York, NY: Routledge.

Taylor, A. (2013). Reconfiguring the natures of childhood. London, UK: Routledge.

Taylor, C. A., \& Hughes, C. (Eds.). (2016). Posthuman research practices in education. Basingstoke, UK: Palgrave Macmillan.

\section{(Endnotes)}

For example, Donna Haraway (2016, pp. 49-57) decenters the anthro in Anthropocene, because even a humananimal never acts alone. She offers eight reasons why she prefers to distance herself from the word Anthropocene and proposes Chthulucene-a tentacular thinking that disrupts the human exceptionalism of the Anthropocene discourse.

Our work is de/colonizing in the ontological sense by disrupting the nature/culture binary and including the nonhuman and more-than-human in the relational ontology that informs our pedagogy. Moreover, our teaching work de/colonizes in the epistemological sense in that our teaching disrupts human exceptionalism, age discrimination (misopedy), misogyny, and racism. Finally, we write de/colonizing because the slash expresses a changed relationality toward truth.

According to Carla Rinaldi (2006, pp. xi, 206), progettazione cannot really be translated. It is a strategy, a daily practice of observation-interpretation-documentation - an emergent curriculum developed by the preschools in Reggio Emilia. Italy.

Building on Haraway's work, Barad (e.g. 2007, 2014) shows how diffraction works in writing and how it disrupts understandings of difference that are based on taxonomies that locate subjects according to natural kinds (Barad, 2014, p. 172). Diffraction means "to break apart in different directions" (Barad, 2007, p.168)-a cutting together-apart (one move) in the (re)configuring of spacetimemattering (Barad, 2014). For Barad, diffraction is not a metaphor as it was for Haraway, but it denotes phenomena of matter itself (Seghal, 2014, p. 188). Waves and particles are not closed and bounded objects but disturbances, and the same holds for a human body — not bounded and isolated from other human and nonhuman bodies.

5 Using different shades of grey and black for printing, $i$ ii indicates that a self is not a bounded singular organism and that a posthuman analysis is not the same as simply adding the material to the discursive (e.g., adding ' $\mathrm{i}$ ' to 'ii' = 'iii'). Describing child as such is not an attempt at a definition.

Unlike arborescent systems of thought and binary logic that have dominated Western epistemological concepts (e.g., root, foundation, ground), rhizomes (e.g., ginger, couch grass, rats) are multiple and move dynamically and unpredictably, ceaselessly establishing connections (Deleuze \& Guattari, 1987/2014, pp. 5-7).

Special Studies is a course that enables experiential learning about teaching, for teaching, and through teaching in schools, on outings, and through community-based practice. 